\title{
Power spectrum analysis of EEG at diagnosis and follow up of patients with solvent induced chronic toxic encephalopathy
}

\author{
P ØRBÆK, ' I ROSÉN, ${ }^{2} \mathrm{~K}$ SVENSSON ${ }^{3}$ \\ From the Department of Occupational Medicine,' Malmö General Hospital, Malmö, Department of Clinical \\ Neurophysiology, ${ }^{2}$ Lund University Hospital, and Department of Statistics, ${ }^{3}$ Lund University, Lund, Sweden
}

ABSTRACT Electroencephalographic changes have been studied in a group of 32 men aged 30-65 (mean 49) with diagnosed chronic toxic encephalopathy. The group had been carefully scrutinised for other possible causes of brain dysfunction and the diagnosis was based on neuraesthenic symptoms and pathological psychometric performance. The EEGs were recorded from four areas of the brain and the power spectrum analysed. Comparisons have been made with a group of 50 healthy male workers with no occupational exposure to solvents. For 24 of the 32 patients a follow up EEG recording was made after 17-75 months (mean 33). The results showed a doubling of the EEG power in the patients for all four recording channels with a significant reduction at follow up but not to the level of the control group. No exposure effect relation could be established. Acute exposure at the time of the first recording, exposure free, or follow up time did not influence the results. The frequency of the dominant EEG activity and the relative frequency distribution were equal in the two groups and did not change during the follow up period. Five of the 32 subjects took benzodiazepine drugs regularly and they had greater total power in all four recording channels compared with the other 27 patients; the difference was not statistically significant. The relative frequency distribution showed less $\alpha$-and more $\theta$-and $\beta$-power in these five subjects. A reduction in total power during follow up was also found in the subgroup that took benzodiazepines. It is concluded that patients with solvent induced chronic toxic encephalopathy have cerebral pathophysiological changes as reflected in the EEG power spectrum. Only a proportion of the changes may be caused by subacute pharmacological solvent effects. Increased EEG total power without change in relative frequency distribution was also shown after an exposure free interval of 17-75 months (mean 33).

The central nervous system effects of long term exposure to mixtures of organic solvents, usually classified as chronic toxic encephalopathy or organic psychosyndrome, has been established in Scandinavia for a decade, although workers in other countries have been more reluctant to accept the concept. ${ }^{12}$ The World Health Organisation and a working group in the United States have suggested classification systems and pointed out the need for further research. ${ }^{34}$

It has not been possible to demonstrate differences between subjects exposed to solvent mixtures and nonexposed control subjects by electroencephalography with visual reading of paper recordings. ${ }^{56}$ In two cross sectional studies a computer processed spectral parameter analysis indicated a lower frequency

Accepted 6 April 1987 stability in workers exposed to jet fuel but no effects in subjects exposed to mixtures of solvents. ${ }^{67}$

We have previously reported increased fast and slow wave activity in visual routine evaluation, confirmed by computed power spectra of the same EEGs. ${ }^{8}$ The increase of $\beta$-activity has also been observed among subjects exposed to styrene. ${ }^{910}$ A prevalence of $67 \%$ abnormal findings and improvement in $47 \%$ during three to nine years follow up in a group diagnosed to have "chronic solvent poisoning" has been reported."

The great variation in "normality" of visual EEG readings makes this method less useful for establishing slight organic brain involvement. Power spectrum analysis by fast Fourier transform has provided the possibility for sensitive and objective measurements of brain function.

The effect of age measured by computed EEGs has 
been described as decreasing central inhibitory function. ${ }^{12}$ Such reaction has also been found in younger subjects during the induction of narcosis ${ }^{13}$ and in groups of alcoholics with increases of EEG total power and relative amount of the $\beta$-frequency. ${ }^{14}$

The objective of the present study was to search for signs of organic brain involvement in subjects with psychometric diagnosis of reduced brain function suggestively caused by previous long term exposure to solvents.

We have used EEG power spectrum analysis with the hypothesis that solvent encephalopathy should have the characteristics of a slight metabolic encephalopathy: increase of power and a change in relative frequency distribution.

\section{Subjects}

From 1976 to 1981,62 patients were given the diagnosis of solvent induced chronic toxic encephalopathy. The diagnosis was based on neuraesthenic symptoms and abnormal performance in psychometric tests preceded by substantial exposure to organic solvents (preferably daily for more than ten years). Only the visual reading of the EEG was known by the clinician and has been used for differential diagnostic purposes only.

The patients have, if possible, been examined and undergone tests every second year. The time course of the psychometric testing and comparisons with healthy controls have been reported previously. ${ }^{1516}$

To avoid suspicion of other causes of brain dysfunction among the subjects, we have kept strictly to the exclusion criteria: severe head trauma, cerebrovascular manifestations, other neurological disorders, diffuse arteriosclerotic signs, alcohol and drug abuse, and any severe psychiatric or somatic disease such as diabetes mellitus and kidney dysfunction. ${ }^{17}$

The differential diagnostic evaluation comprised an extensive neurological examination, ${ }^{17 \mathrm{a}}$ measurements of $\mathrm{rCBF},{ }^{176}$ computed brain tomography, ${ }^{16}$ and clinical chemistry. All available hospital files were examined. Finally our social worker made a social evaluation by interviewing the patients and families at home ( $G$ Åbjörnsson, personal communication).

As 19 patients were excluded and 10 subjects refused to participate in the complete follow up examination, the final group with diagnosed chronic toxic encephalopathy comprised 32 men aged 30-65 (mean 49) at first examination. ${ }^{16}$ Twenty four were re-examined after 17-75 months (mean 33) and by then had not been exposed to solvents for 3-93 months (mean 36). The loss of eight subjects in the follow up was caused by an administrative mistake resulting in only paper recordings of the follow up EEGs.

According to the classification suggested in the
United States the patients were type $2 b .{ }^{4}$ Alcohol consumption was less than $200 \mathrm{~g} / \mathrm{w}$ for 26 subjects and less than $400 \mathrm{~g} / \mathrm{w}$ for the remaining six. Seven subjects were using central nervous system active drugs when the EEG was recorded. Five were taking a benzodiazepine to induce sleep, and one took a benzodiazepine tranquiliser also during the day. The two remaining subjects were taking propiomazine (Propavan). Ten other subjects were taking regular medication: cardiovascular drugs (5), non-narcotic analgesics (2), blood lipid reducing drug (1), thyroid hormone substitution (1), and $\beta$-2-bronchodilating inhalations (1). Fifteen subjects did not take drugs regularly.

The control group consisted of 50 men aged 27-64 (mean 42) from the same socioeconomic level as the study group. They had never been professionally exposed to solvents and all were in good health with no neurological deficits. ${ }^{8}$ Alcohol consumption was less than $200 \mathrm{~g} / \mathrm{w}$ for 44 subjects and less than $400 \mathrm{~g} / \mathrm{w}$ for the remaining six. Two subjects took sedatives occasionally.

\section{Exposure}

Before seeking help for their neuraesthenic and affective symptoms the subjects had been exposed to solvents every day for seven to 50 years (median 26). No measurements had been made at their workplaces when they came to the department for the first time during 1976-81. At the time of the follow up examination (1984-5) the relevant levels of exposure no longer existed or the workplaces had disappeared. For investigating exposure response relation we have used a model suggested in an epidemiological study using exposure intensity factors ${ }^{18}$ (table 1 ). Factors not calculated by Ravnskov et $a l^{18}$ have been estimated by our occupational hygienist Gun Nise (personal communication). An exposure index has been calculated

Table 1 Occupations of exposure and intensity factors

\begin{tabular}{lll}
\hline & \multicolumn{2}{l}{ Exposure intensity } \\
\cline { 2 - 3 } & No & Factor \\
\hline Industrial spray painter & 8 & $2^{*}$ \\
Car repair spray painter & 7 & $2^{* \dagger}$ \\
House painter (indoor) & 5 & 2 \\
Paint industry worker & 5 & 2 \\
Floor layer & 2 & 2 \\
Tank cleaner/painter & 1 & $2 \dagger$ \\
Dry cleaner & 1 & 1 \\
Joiner & 1 & $1+$ \\
Grinder/degreaser & 1 & 1 \\
Car mechanic/sheet metal worker & 1 & $0 \cdot 5$ \\
\hline
\end{tabular}

*Estimated without respirator. With use of respirator the intensity factor is set to 1 .

†Not included in the paper by Ravnskov et al. 
by multiplying years of exposure with the intensity factor giving indices for the group ranging from 12 to $100($ mean $46, S D=23)$.

\section{Methods}

EEG recording was performed under standard conditions on a 16-channel Siemens Elema electroencephalograph at rest and during three minutes of hyperventilation and photoactivation. Periods of drowsiness were counteracted by sound stimulation. During 10 minutes at rest with closed eyes quantitative frequency analysis was made on line from two bipolar channels on each side of the skull (Ch1:F3-C3, Ch2:P3-O1, Ch3:F4-C4, Ch4:P4-O2). Fast Fourier transform analysis was made with the Brainlab program (Digital Equipment AB) on a PDP 11/03 computer. The total power of the EEG activity within the $0.5-25 \mathrm{~Hz}$ range was measured, as well as the relative distribution of power within four frequency ranges $(\delta 0 \cdot 5-4 \mathrm{~Hz}, \theta 4 \cdot 1-8 \mathrm{~Hz}, \alpha 8 \cdot 1-13 \mathrm{~Hz}, \beta 13 \cdot 1-25$ $\mathrm{Hz}$ ). From these values the absolute power within each frequency range was calculated. The median frequency of the dominant activity for each of the four channels was also determined.

To test the possibility of an altered distribution of activity over the brain, anteroposterior quotients were calculated for the total power and for each of the four frequency bands. No quotients were constructed with power values less than $1 \mathrm{pW}$. The patients and the controls were examined using the same equipment and by the same laboratory staff.

\section{Data analysis}

Comparisons between groups were performed with Student's $t$ test using corrections for unequal variance where appropriate. Comparisons within groups were performed using Student's paired $t$ test. Covariations between time variables and EEG measures were investigated by correlation analysis. Subgroups within the patient group were compared by use of MannWhitney's U test. All $p$ values given are two sided.

The analysis of missing data showed a random

Table 2 Results of quantitative frequency analysis of EEG. Frequency of dominant activity and power in the four frequency bands in the four channels

\begin{tabular}{|c|c|c|c|c|c|c|}
\hline & \multirow{2}{*}{\multicolumn{2}{|c|}{ Controls $(n=50)$}} & \multicolumn{4}{|c|}{ Patients with toxic encephalopathy } \\
\hline & & & \multicolumn{2}{|c|}{ Diagnosis $(n=32)$} & \multicolumn{2}{|c|}{ Follow up $(n=24)$} \\
\hline & Mean & $S D$ & Mean & $S D$ & Mean & $S D$ \\
\hline \multicolumn{7}{|l|}{ Chl (F3-C3) } \\
\hline $\begin{array}{l}\text { Frequency } \mathrm{Hz} \\
\text { Total power pW } \\
\delta \mathrm{pW} \\
\theta \mathrm{pW} \\
\alpha \mathrm{pW} \\
\beta \mathrm{pW}\end{array}$ & $\begin{array}{r}9 \cdot 56 \\
12.33 \\
5.96 \\
1.42 \\
3.57 \\
2 \cdot 16\end{array}$ & $\begin{array}{r}1 \cdot 34 \\
12 \cdot 36 \\
6 \cdot 38 \\
1 \cdot 40 \\
5 \cdot 14 \\
3 \cdot 11\end{array}$ & $\begin{array}{l}9 \cdot 45 \\
27 \cdot 38^{* * *} \\
10 \cdot 10^{*} \\
4 \cdot 81^{* * *} \\
8 \cdot 33^{* * *} \\
4 \cdot 14^{*}\end{array}$ & $\begin{array}{c}1 \cdot 2 \\
23 \cdot 63 \\
9 \cdot 78 \\
6 \cdot 12 \\
8 \cdot 54 \\
5 \cdot 22\end{array}$ & $\begin{array}{l}9 \cdot 40 \\
20 \cdot 79+\dagger \\
6 \cdot 22 \dagger \dagger \\
2 \cdot 99 \dagger \dagger \\
7 \cdot 83 \\
3 \cdot 63+\dagger\end{array}$ & $\begin{array}{r}1 \cdot 07 \\
17 \cdot 29 \\
4 \cdot 50 \\
4 \cdot 06 \\
9 \cdot 97 \\
4 \cdot 19\end{array}$ \\
\hline \multicolumn{7}{|l|}{$\begin{array}{l}\mathrm{Ch} 2(\mathrm{P} 3-\mathrm{O} 1) \\
\text { Dominant }\end{array}$} \\
\hline $\begin{array}{l}\text { Frequency } \mathrm{Hz} \\
\text { Total power pW } \\
\delta \text { pW } \\
\theta \text { pW } \\
\alpha \text { pW } \\
\beta \text { pW }\end{array}$ & $\begin{array}{r}9.67 \\
14.57 \\
3.69 \\
1.53 \\
8.82 \\
0.63\end{array}$ & $\begin{array}{r}1 \cdot 21 \\
17 \cdot 98 \\
4.43 \\
2.08 \\
13.87 \\
0.70\end{array}$ & $\begin{array}{c}9 \cdot 72 \\
30 \cdot 74^{* * *} \\
9 \cdot 98^{* *} \\
5 \cdot 67^{* *} \\
12 \cdot 27 \\
2 \cdot 81^{* *}\end{array}$ & $\begin{array}{r}1 \cdot 15 \\
29 \cdot 59 \\
12.64 \\
9.65 \\
16.23 \\
4.99\end{array}$ & $\begin{array}{l}9.53 \\
23 \cdot 75+t \\
6 \cdot 5 t \\
3 \cdot 08+t \\
12 \cdot 06 \\
2 \cdot 11 \dagger\end{array}$ & $\begin{array}{r}0.90 \\
26.81 \\
6.09 \\
3.94 \\
18.94 \\
3.25\end{array}$ \\
\hline \multicolumn{7}{|l|}{$\begin{array}{l}\mathrm{Ch} 3(\mathrm{~F} 4-\mathrm{C} 4) \\
\text { Dominant }\end{array}$} \\
\hline $\begin{array}{l}\text { Frequency } \mathrm{Hz} \\
\text { Total power pW } \\
\delta \mathrm{pW} \\
\theta \mathrm{pW} \\
\alpha \mathrm{pW} \\
\beta \mathrm{pW}\end{array}$ & $\begin{array}{r}9 \cdot 62 \\
12.58 \\
5 \cdot 75 \\
1.55 \\
3.92 \\
1.75\end{array}$ & $\begin{array}{l}1 \cdot 30 \\
9 \cdot 55 \\
3 \cdot 70 \\
1 \cdot 42 \\
5 \cdot 28 \\
1 \cdot 64\end{array}$ & $\begin{array}{l}9 \cdot 58 \\
29 \cdot 22^{* * *} \\
9 \cdot 79^{*} \\
5 \cdot 45^{* * *} \\
8 \cdot 79^{* *} \\
5 \cdot 15^{* * *}\end{array}$ & $\begin{array}{r}1 \cdot 16 \\
26 \cdot 53 \\
10 \cdot 51 \\
7 \cdot 84 \\
9 \cdot 09 \\
6 \cdot 19\end{array}$ & $\begin{array}{l}9 \cdot 48 \\
22 \cdot 46+\dagger \\
6 \cdot 24 \dagger \dagger \\
3 \cdot 02+t \dagger \\
9 \cdot 05 \\
4 \cdot 10+\dagger\end{array}$ & $\begin{array}{r}1 \cdot 00 \\
19 \cdot 95 \\
4 \cdot 14 \\
3 \cdot 74 \\
13 \cdot 37 \\
4 \cdot 86\end{array}$ \\
\hline \multicolumn{7}{|l|}{$\begin{array}{l}\text { Ch4 (F4-O2) } \\
\text { Dominant }\end{array}$} \\
\hline $\begin{array}{l}\text { Frequency } \mathrm{Hz} \\
\text { Total power pW } \\
\delta \mathrm{pW} \\
\theta \mathrm{pW} \\
\alpha \mathrm{pW} \\
\beta \mathrm{pW}\end{array}$ & $\begin{array}{r}9.68 \\
15 \cdot 14 \\
3.44 \\
1.53 \\
9.77 \\
0.68\end{array}$ & $\begin{array}{r}1 \cdot 18 \\
17.08 \\
4.49 \\
2.02 \\
13.90 \\
0.65\end{array}$ & $\begin{array}{c}9 \cdot 67 \\
27 \cdot 52^{* *} \\
7 \cdot 77^{* *} \\
5 \cdot 02^{* *} \\
12 \cdot 0 \\
2 \cdot 74^{* *}\end{array}$ & $\begin{array}{r}1 \cdot 16 \\
26 \cdot 71 \\
11 \cdot 11 \\
7 \cdot 49 \\
16 \cdot 15 \\
4 \cdot 44\end{array}$ & $\begin{array}{r}9.68 \\
25 \cdot 61 \\
6 \cdot 12 \\
4.45 \\
12.41 \\
2.61\end{array}$ & $\begin{array}{r}0.84 \\
25.32 \\
5 \cdot 45 \\
6.52 \\
17.08 \\
3.55\end{array}$ \\
\hline
\end{tabular}

Significance levels in group comparisons with $t$ test for unequal variances ${ }^{*} p<0.1, * * p<0.05, * * *<<0.01$

Significance levels $t$ test for paired data in comparisons between the two examinations $\dagger p<0.1,+\dagger p<0.05, \dagger+\dagger p<0.01$. 
pattern of minor frequency. Nevertheless, the frequency was large enough to invalidate any multivariate approach to the data. Thus the results are shown variable by variable. When analysing a substantial number of variables one by one, the problem of mass significance should always be considered. The pattern of significant results should be considered on the whole rather than single occurrences among the variables.

\section{Results}

Power spectrum analysis showed an increase of EEG total power in all four recording channels in the patients compared with the controls (table 2). The increase in power was statistically significant in most recordings except for the $\alpha$-band in the posterior recording channels $(\mathrm{Ch} 2, \mathrm{Ch} 4)$; the increase in frontal $\delta$ - $(\mathrm{Ch} 1, \mathrm{Ch} 3)$ and frontal left $\beta$-band (Ch1) was close to conventional levels of statistical significance (table 2 and figure).

The relative power distribution and the frequency of dominant activity were equal in the two groups (tables 2,3 ) as were the anteroposterior power distributions of all frequency bands (table 4).
At follow up 17-75 months (mean 33) later the total EEG power had decreased statistically significantly in three channels (Ch1, Ch2, Ch3) but not in the right posterior recording channel (Ch4) and not to the level of the controls (table 2). No significant changes in frequency distribution, peak frequency, or anteroposterior distributions of power were found during follow up (tables 3, 4). The power reduction of the frequency bands was more pronounced anteriorly in the $\delta$-band that decreased to normal values at follow up (figure). The $\alpha$-power remained constant after cessation of exposure.

None of the EEG measures at diagnosis or changes during follow up was related to the subjects' age and the exposure index did not covariate with any results from the first recordings and only to one change during follow up (right anteroposterior $\delta$-quota). This observation seems to be sporadic due to mass significance and without biological meaning.

Finally, the influence of follow up time was investigated by analyses of correlation between the differences of the two EEG measurements and the follow up time. Statistically significant correlations were found in $\mathrm{Chl}$ for the frequency of dominant activity $(\mathrm{r}=$ $0.45, \mathrm{p}=0.03)$, in Ch2 for total power $(\mathrm{r}=0.46, \mathrm{p}=$ $0.01)$ and $\delta$-power $(\mathrm{n}=0.53, \mathrm{p}=0.009)$, and in $\mathrm{Ch} 4$
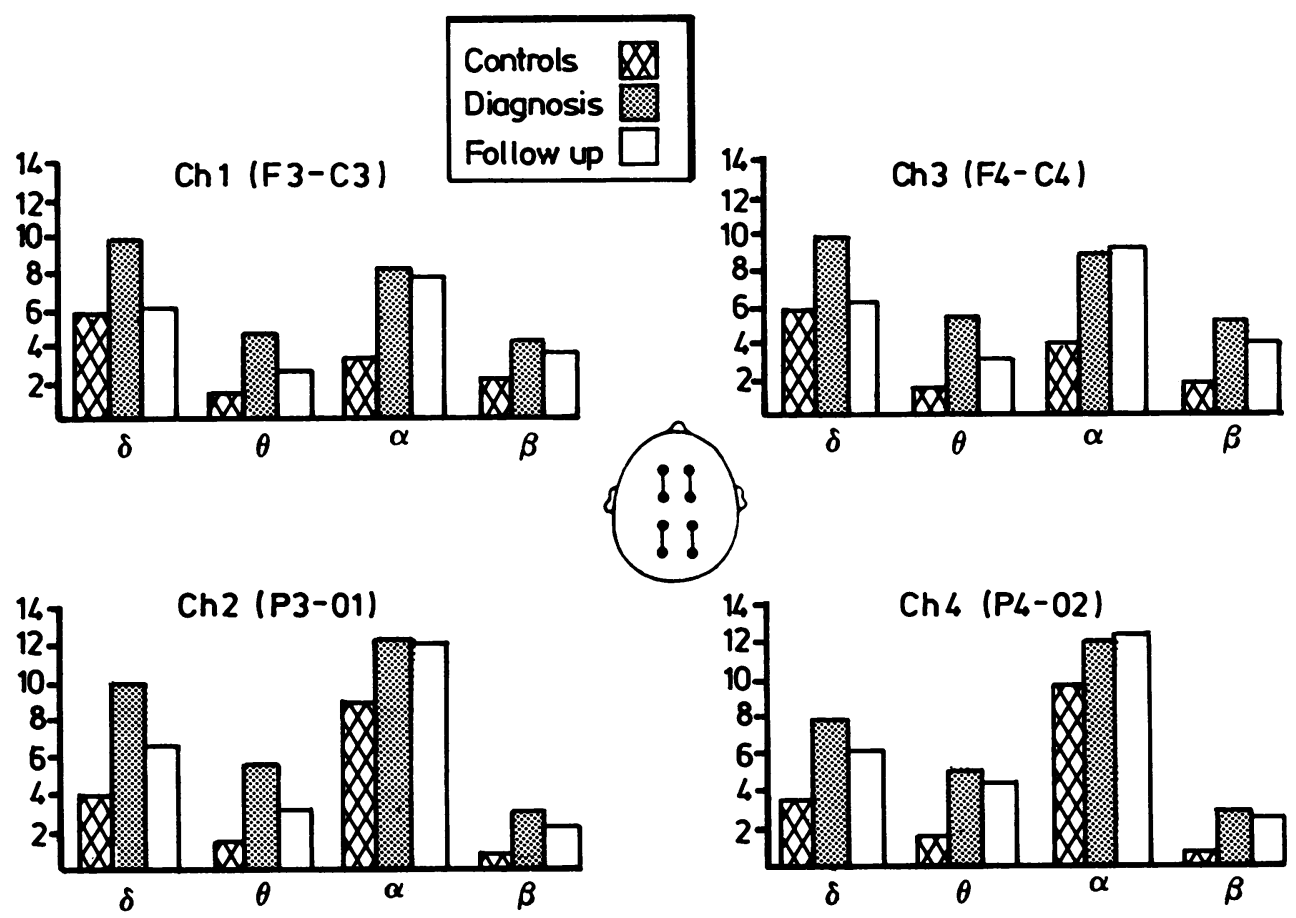

Absolute EEG power ( $p W a t t$ ) of four frequency bands in four channels for controls and patients at first and follow up examinations. (For details see table 2.) 
Table 3 Results of quantitative frequency analysis of EEG. Relative power distribution in the four channels of the four frequency bands

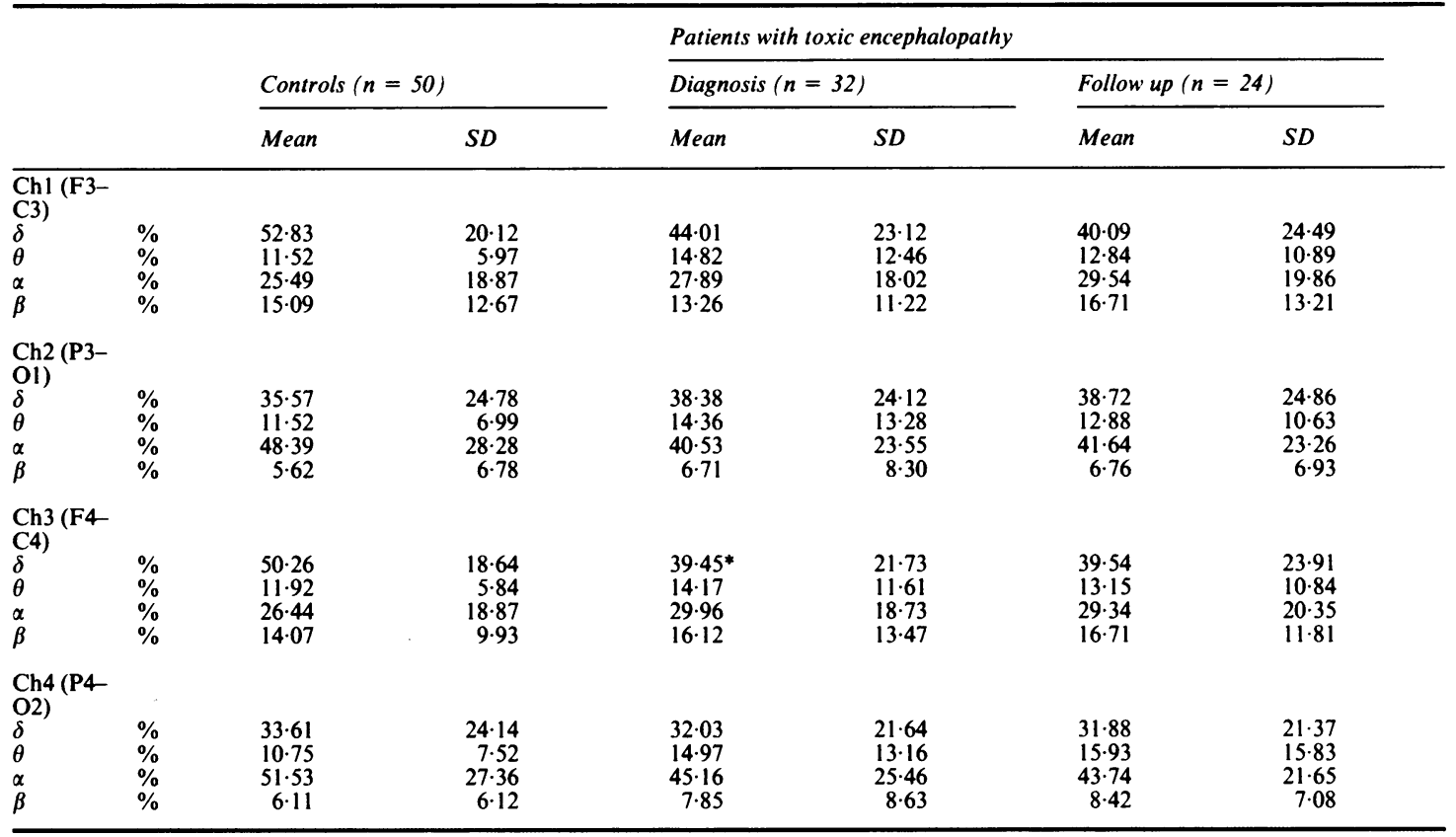

Significance level in group comparisons with $t$ test for unequal variances * $p<0.05$.

No difference between the two examinations of the patients was statistically significant.

Table 4 Results of quantitative frequency analysis of EEG. Analysis of anteroposterior power distributions calculated as quotients of anterior and posterior power in each frequency band. Power registrations below 1 pW are excluded from the calculations of the quota

\begin{tabular}{|c|c|c|c|c|c|c|}
\hline \multirow{3}{*}{-} & \multirow{2}{*}{\multicolumn{2}{|c|}{ Controls $(n=50)$}} & \multicolumn{4}{|c|}{ Patients with toxic encephalopathy } \\
\hline & & & \multicolumn{2}{|c|}{ Diagnosis $(n=32)$} & \multicolumn{2}{|c|}{ Follow up $(n=24)$} \\
\hline & Mean & $S D$ & Mean & $S D$ & Mean & $S D$ \\
\hline $\begin{array}{l}\text { Left hemisphere } \\
\text { Total power } \\
\delta \\
\theta \\
\alpha \\
\beta\end{array}$ & $\begin{array}{l}1 \cdot 37 \\
2 \cdot 27 \\
1 \cdot 67 \\
0 \cdot 89 \\
4 \cdot 28\end{array}$ & $\begin{array}{l}1 \cdot 02 \\
1 \cdot 51 \\
1 \cdot 70 \\
0.92 \\
6.02\end{array}$ & $\begin{array}{l}1 \cdot 16 \\
1.62 \\
2.65 \\
0 \cdot 81 \\
3 \cdot 27^{*}\end{array}$ & $\begin{array}{l}0.77 \\
1.29 \\
8.53 \\
0.60 \\
5.40\end{array}$ & $\begin{array}{l}1 \cdot 20 \\
1 \cdot 43 \\
2 \cdot 81 \\
1 \cdot 49 \\
4 \cdot 01+\end{array}$ & $\begin{array}{l}0.61 \\
1 \cdot 21 \\
7.46 \\
2.81 \\
5.85\end{array}$ \\
\hline $\begin{array}{l}\text { Right hemisphere } \\
\text { Total power } \\
\delta \\
\theta \\
\alpha \\
\beta\end{array}$ & $\begin{array}{l}1 \cdot 52 \\
2 \cdot 43 \\
2 \cdot 80 \\
0 \cdot 80 \\
2 \cdot 86\end{array}$ & $\begin{array}{l}1 \cdot 89 \\
1 \cdot 85 \\
5 \cdot 26 \\
0.90 \\
2 \cdot 53\end{array}$ & $\begin{array}{l}1.36 \\
2.00 \\
2.09 \\
0.95 \\
6.44 \ddagger\end{array}$ & $\begin{array}{r}1.00 \\
1.61 \\
4.64 \\
0.70 \\
14.98\end{array}$ & $\begin{array}{l}1.07 \\
1.48 \\
1.05 \\
0.79 \\
2.74 \$\end{array}$ & $\begin{array}{l}0.74 \\
1 \cdot 13 \\
0.86 \\
0.85 \\
2 \cdot 75\end{array}$ \\
\hline
\end{tabular}

*n $=23,+\mathrm{n}=17, \pm \mathrm{n}=26, \S \mathrm{n}=20$.

No difference between the two groups or between the two examinations of the patient group was statistically significant.

$\delta$-power $(\mathrm{r}=0.54, \mathrm{p}=0.008)$. The time dependency seems thus to be more pronounced in the posterior recordings but a clear pattern is not apparent.

The five subjects taking benzodiazepines had greater total power in all four channels compared with Ch2:64.4, Ch3:51·2, Ch4:56.9). They also tended to have relatively less $\alpha$-and more $\theta$ - and $\beta$-power. None of these differences was statistically significant.

Excluding the five subjects taking benzodiazepines 
from the statistical analysis did not change the results described above. Differences from the control group were still statistically significant. These five subjects also had significant reductions of total power after ending their exposure to solvents.

\section{Discussion}

The main importance of the present study is the extension of the clinical and psychometric diagnosis of toxic encephalopathy into the pathophysiological realm. By use of objective EEG recordings we have shown a diffuse organic brain involvement in subjects with long term exposure to mixtures of organic solvents. The change in brain function indicated by the observed increase of EEG power is long lasting after cessation of exposure.

In a group of currently exposed paint industry workers we have found a slight increase in total power which was more pronounced in posterior channels. ${ }^{8}$ The increase in the present patient group being larger and with no antero-posterior differences is thus more generalised. When the exposure was discontinued the power did not decrease to the levels of either unexposed or the currently exposed subjects in our previous study. ${ }^{8}$ We interpret this stepwise reaction to exposure to solvents as a sign of increasing brain involvement. A similar stepwise increase of function impairment has been measured with rCBF. Subjects currently being exposed had, on average, a $4 \%$ flow reduction. ${ }^{8}$ In the present group a reduction of $7 \%$ has been found. ${ }^{17 b}$ The blood flow measures were closer to the control values when exposure was discontinued. ${ }^{17 \mathrm{~b}}$ We did not find any regional correlation between $\mathrm{rCBF}$ and EEG power.

The solvent effects on the rhythm generators at occupational exposure levels seem to be a release phenomenon. The release of rhythmic activity is comparable with that in mild metabolic encephalopathies and to the changes seen with use of hypnotics and sedatives. ${ }^{1920}$ Induction of narcosis shows a similar release of rhythmic activity followed by depression in the deeper narcotic stages. ${ }^{13} \mathrm{~A}$ release phenomenon could be the explanation of the increased visually evoked potential amplitudes found by Elofsson $e t a l$ in subjects exposed to solvents. ${ }^{6}$ In users of sedatives and in alcoholics the power increase is followed by a change in relative power distribution such as less $\alpha$ and more $\beta$ activity. ${ }^{142122}$ Frequency distribution changes were not found in our patients with chronic toxic encephalopathy.

The more pronounced power increase among subjects taking benzodiazepines in the present study suggests a synergistic effect with the solvents. The time course in this small subgroup is the same as for the remaining patients who did not take benzodiazepine drugs.

In toxicological studies it is desirable to show a dose response relation. In non-experimental designs such as the one used here we have found great difficulty in describing exposure in a valid way. We did not even succeed in using the complete model suggested by Ravnskov et al. ${ }^{18}$ The subjects' recapitulation at the follow up interviews of their previous work conditions over decades varied to a substantial degree from those given on their first visit to the department of occupational medicine in interviews with various physicians. For this reason we have used only the number of years in each occupation for calculating the dose index.

The individual susceptibility to toxic substances depends on numerous genetic and metabolic predispositions. The psychological reaction to the pharmacological effect of the solvents is dependent on personality, previous experiences, social network, and culture. These confounders make it almost impossible to show a classic exposure-effect relation in studies such as the one described here or in cross sectional epidemiological studies of neurotoxic effects. The poor correlation between EEG changes and drug blood concentration emphasises the problem. ${ }^{23}$

Many subjects in the present study had been less exposed to solvents than the paint industry workers we had examined previously. ${ }^{8}$ Despite this we found, as expected, larger EEG changes in the patients. The brain reaction suggests a higher degree of individual susceptibility, which under unfavourable circumstances predisposes the subject to chronic solvent induced brain dysfunction.

The diagnostic procedure with clinical and psychometric evaluation of subjects exposed to solvents has been questioned. It has been postulated that workers with solvent exposure represent a negative selection. ${ }^{24} 25$ Our results clearly refute those arguments by the demonstration of chronic pathophysiological changes. We have, however, previously discussed the importance of careful adjustments for premorbid intellectual capacity when psychometric results are compared with those from control subjects. ${ }^{1626}$

We conclude that encephalopathic patients selected on the basis of their symptoms and psychometric test performance and submitted to careful differential diagnostic evaluation do show pathophysiological changes. A proportion of these changes is probably caused by subacute pharmacological solvent effects. Chronic increase in EEG total power without change in relative power distribution, however, was also shown after an exposure free interval of 17-75 months (mean 33).

We thank Professor Birgitta Haeger-Aronsen who 
introduced us to the problem and the subjects examined. The study was supported by grants from the Swedish Work Environment Fund (ASF 80-072, ASF 82-1011).

Requests for reprints to: Dr Palle Ørbæk, Yrkesmedicinska kliniken, Malmö allmänna sjukhus, S-214 01 Malmo.

\section{References}

1 Grasso P, Sharratt M, Davies DM. Neurophysiological and psychological disorders and occupational exposure to organic solvents. Food Chem Toxicol 1984;22:819-52.

2 Spencer PS, Schaumburg HH. Organic solvent neurotoxicity. Facts and research needs. Scand J Work Environ Health 1985;11 (suppl 1):53-60.

3 Joint WHO/Nordic Council of Ministers Working Group. Organic solvents and the central nervous system. Copenhagen: World Health Organisation, 1985. (Environmental health document 5.)

4 Waldron HA. Solvents and the brain. Br J Ind Med 1986;43:73-4.

5 Seppäläinen AM, Husman K, Mårtensson C. Neurophysiological effects of long-term exposure to a mixture of organic solvents. Scand J Work Environ Health 1978;4:304-14.

6 Elofsson SA, Gamberale F, Hindmarsh T, et al. Exposure to organic solvents. A cross-sectional epidemiologic investigation on occupationally exposed car and industrial spray painters with special reference to the nervous system. Scand J Work Environ Health 1980;6:239-73.

7 Knave B, Anshelm Olson B, Elofsson S, et al. Long-term exposure to jet fuel II. A cross-sectional epidemiologic investigation on occupationally exposed industrial workers with special reference to the nervous system. Scand J Work Environ Health 1978;4:19-45.

8 Ørbæk R, Risberg J, Rosén I, et al. Effects of long-term exposure to solvents in the paint industry. A cross-sectional epidemiologic study with clinical and laboratory methods. Scand J Work Environ Health 1985;11 (suppl 2):28.

9 Rosén I, Haeger-Aronsen B, Rehnström S, Welinder H. Neurophysiological observations after chronic styrene exposure. Scand J Work Environ Health 1978;4 (suppl 2):184-94.

10 Seppäläinen AM, Lindström K, Martelin T. Neurophysiological and psychological picture of solvent poisoning. Am J Ind Med 1980;1:31-42.

11 Seppäläinen AM, Antti-Poika M. Time course of electrophysiological findings for patients with solvent poisoning. A descriptive study. Scand J Work Environ Health 1983;9:15-24.

12 Dustman RE, LaMarche JA, Cohn NB, Shearer DE, Talone JM. Power spectral analysis and cortical coupling of EEG for young and old normal adults. Neurobiol Aging 1985;6:193-8.

13 Levy WJ. Power spectrum correlates of changes in consciousness during anaesthetic induction with enflurane. Anesthesiology 1986:64:688-93.
14 Kaplan RF, Glueck BC, Hesselbrock MN, Reed HBC. Power and coherence analysis of the EEG in hospitalized alcoholics and nonalcoholic controls. J Stud Alcohol 1985;46:122-7.

15 Lindgren M, Ørbæk P, Haeger-Aronsen B. Prospective psychometric investigation of patients with organic psycho-syndrome due to organic solvents. Copenhagen: World Health Organisation, 1985:124-9. (Environmental health document 3.)

16 Ørbæk P, Lindgren M, Olivecrona H, Haeger-Aronsen B. Computed brain tomography and psychometric test performances in patients with solvent induced chronic toxic encephalopathy and healthy controls. $\mathrm{Br}$ J Ind Med 1987;44:175-9.

17 Wells CE. Diagnostic evaluation and treatment in dementia. In: Wells CE, ed. Dementia. Philadelphia: FA Davis Company, 1977:247-76.

17a Ørbæk P, Lindgren M. Prospective clinical and psychometric investigation of patients with solvent induced chronic toxic encephalopathy. Scand J Work Environ Health 1988;14:37-44.

17b Hagstadius S, Ørbæk P, Risberg J, Lindgren M. Regional cerebral blood flow in organic solvent induced chronic toxic encephalopathy at the time of diagnosis and following cessation of exposure. Scand J Work Environ Health (in press).

18 Ravnskov U, Forsberg B, Skerfving S. Glomerulonephritis and exposure to organic solvents. A case-control study. Acta Med Scand 1979;205:575-9.

19 Nidermeyer E. Metabolic central nervous system disorders. In Niedermeyer E, Lopes da Silva F, eds. Electroencephalography. Basic principles, clinical applications and related fields. Baltimore-Munich: Urban \& Swarzenberg, 1982:305-18.

20 Buchsbaum MS, Hazlett E, Sicotte N, Stein M, Wu J, Zetin M. Topographic EEG changes with benzodiazepine administration in generalized anxiety disorders. Biol Psychiatry 1985;20: $832-42$.

21 Coger RW, Dymond AM, Serafetinides EA, Lowenstam I, Pearson D. EEG signs of brain impairment in alcoholism. Biol Psychiatry 1978:13:729-39.

22 Zilm DH, Huszar L, Carlen PL, Kaplan HL, Wilkinson DA. EEG correlates of alcohol-induced organic brain syndrome in man. Clinical Toxicology 1980;16:345-58.

23 Sannita WG, Balestra V, Rosadini G, Salama M, Timitilli C. Quantitative EEG and neuropsychological effects of piracetam and of the association piracetam-lecithin in healthy volunteers. Neuropsychobiology 1985;14:203-9.

24 Gade A, Mortensen EL, Udesen H, Bruhn P. On the importance of control data and background variables in the evaluation of neuropsychological aspects of brain functioning. Copenhagen: World Health Organisation, 1985:91-6. (Environmental health document 3.)

25 Errebo-Knudsen EO, Olsen F. Organic solvents and presenile dementia (the painters syndrome). A critical review of the Danish literature. Sci Total Environ 1986;48:45-67.

26 Åslund U, Ørbæk P, Nise G, Wahlgren L. Psychometric assessment of toxic encephalopathy: standardization by reference equations. In: Abstracts of 2 nd international symposium on neurobehavioral methods in occupational and environmental health, Copenhagen, 1985. Copenhagen: World Health Organisation, 1985. 